\title{
Notas sobre a morfologia floral e a fenologia do bacurizeiro (Platonia insignis Mart.) Clusiaceae, no município de Bragança, estado do Pará Notes on the floral morphology and phenology of Bacurizeiro (Platonia Insignis Mart.) Clusiaceae in Bragança, Pará
}

Resumo: São apresentadas informações sobre a morfologia floral e a fenologia de floração e frutificação de Platonia insignis Mart. em floresta secundária. A pesquisa foi conduzida na comunidade de Benjamin Constant, localizada no município de Bragança, nordeste do Pará, durante o período de agosto de 2001 a julho de 2002. Foram selecionados sete indivíduos de uma população natural e, com o auxilio de um binóculo e duas torres para observação, avaliou-se a fenologia desde o aparecimento dos botões florais até a maturação total dos frutos. A morfologia da flor foi feita com auxilio de microscópio estereoscópico. A flor de Platonia insignis Mart. é hermafrodita, vistosa, solitária, de cor rosada, situada em ramos terminais, pedunculada, cíclica, de simetria radial. Floresceu de agosto a dezembro e frutificou de novembro a março. A espécie apresentou sincronismo parcial e padrão anual, tanto na floração quanto na frutificação.

Palavras-chave: Morfologia floral. Vegetação secundária. Platonia insignis. Fenologia.

Abstract: Information on floral morphology, fruiting and flowering phenology were presented. This research was carried out in a natural population located in Benjamin Constant community, municipality at Bragança, northeast of Pará State. Seven individuals of natural population were studied on phenology since this appearing of floral button at fruiting maturation. This description of floral morphology was made with lupa ZEISS. Platonia insignis Mart. is hermafrodite, showy flowers, solitary and roseate located in branch terminals, pedunculate, cyclical and radial simetry; flowering from August to December and fruiting from November to March. This specie presented partial synchronism and annual pattern for flowers and fruits.

Keywords: Floral morphology. Secondary vegetation. Platonia insignis. Phenology.

\footnotetext{
I Museu Paraense Emílio Goeldi. Coordenação de Botânica. Bolsista de Iniciação Científca/CNPq. Belém, Pará, Brasil (fabiojb@superig.com.br).

II Museu Paraense Emílio Goeldi. Coordenação de Botânica. Pesquisador. Belém, Pará, Brasil (jardim@museu-goeldi.br).
}

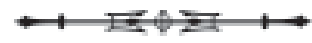




\section{INTRODUÇÃO}

Platonia insignis Mart. pertence à familia Clusiaceae e é conhecida, popularmente, como 'bacurizeiro'. É uma árvore frutífera, com cerca 15 a 25 m de altura e até $1 \mathrm{~m}$ de diâmetro (CAVALCANTE, 1988). Ocorre em áreas abertas, clareiras e, principalmente, na vegetação secundária, sendo rara na floresta primária densa. É uma das frutas mais populares no estado do Pará, com rendimento industrial de 10\% em polpa, 26\% de semente e $64 \%$ de casca. Os frutos podem ser aproveitados na fabricação de refresco, sorvete, geléia, compota e doce e são provenientes do extrativismo de populações nativas. Estudos silviculturais tentam estabelecer critérios de manejo, no nordeste paraense, por meio de mudanças no espaçamento entre indivíduos durante o cultivo, de maneira que possa contribuir no aumento da quantidade de frutos por árvore. Embora esse procedimento ainda não tenha comprovação e eficácia quanto à produção, é importante priorizar informações sobre os aspectos reprodutivos da espécie no sentido de conhecer a época de floração e frutificação, assim como os padrões estruturais da flor. De posse desses conhecimentos, será possível estabelecer indicadores de produção mais coerentes com a biologia da espécie. Este trabalho teve como objetivo obter informações sobre a morfologia floral, a fenologia de floração e frutificação para subsidiar o manejo e, conseqüentemente, a preservação da espécie.

\section{MATERIAL E MÉTODOS}

\section{Área de estudo}

A pesquisa foi desenvolvida na comunidade de Benjamin Constant, município de Bragança, ocupando os vales dos rios Tijoca e Urumajó, localizando-se a leste da Região Bragantina e a $25 \mathrm{~km}$ a sudeste da cidade de Bragança (MONTSERRAT RIOS, 2001) nas coordenadas geográficas 01011'22" de latitude sul e 46 $40^{\prime} 41^{\prime \prime}$ de longitude oeste de Greenwich.

O município de Bragança apresenta o clima equatorial superúmido, com temperaturas máxima de $33^{\circ} \mathrm{C}$, mínima de $18^{\circ} \mathrm{C}$ e média de $27^{\circ} \mathrm{C}$, com índice pluviométrico elevado de $2.501 \mathrm{~mm} / \mathrm{ano}$, com período chuvoso nos primeiros meses do ano (SECTAM, 1999). Os solos são ácidos e fortemente ácidos, de boa drenagem por serem permeáveis e de baixa fertilidade natural por serem Latossolo Amarelo (MONTSERRAT RIOS, 2001). A predominância é de solos de terra firme, apresentando, também, solos de mangue nas proximidades do litoral, hidromórficos e aluviais (SECTAM, 1999).

Atualmente, a paisagem é caracterizada pela predominância de sistemas agrícolas, combinados com capoeiras em vários estágios de sucessão (MONTSERRAT RIOS, 2001), especialmente no planalto costeiro. A cobertura vegetal da comunidade de Benjamin Constant é similar à vegetação do planalto costeiro do município de Bragança. Nessa localidade, encontram-se capoeiras em diferentes estágios de sucessão, buritizais, açaizais e vegetação característica de planícies aluviais inundadas. Para as comunidades agrícolas de Bragança, a capoeira representa 79\% do uso da terra para subsistência, enquanto que $6 \%$ do igapó, $13 \%$ de cultivos (anuais, semiperenes e perenes) e $2 \%$ de pastos são utilizados como outras formas de renda (CARVALHEIRO et al., 2001).

\section{Procedimentos}

Foram selecionados sete indivíduos em fase reprodutiva de uma população nativa com características fenotípicas desejáveis (boa formação de fuste e copa). De cada indivíduo foram coletados botões florais e flores abertas para realização da descrição floral, que foi desenvolvida com auxilio de microscópio estereoscópico ZEISS no laboratório de Botânica do Museu Paraense Emílio Goeldi (MPEG), segundo a metodologia de Vidal e Rodrigues (2000). Em seguida, todo o material reprodutivo coletado foi fixado em álcool a 70\%. Na fenologia, as observações ocorriam duas vezes ao mês, com início em agosto de 2001 perdurando até julho de 2002, no período diurno, com auxílio de um binóculo (TASCO 12×50 mm ZIP FOCUS) em pontos

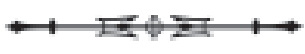


estratégicos próximos às árvores ou nas torres de madeira. Consideraram-se como parâmetros para a floração desde a formação do botão floral até a senescência das flores e, para a frutificação, desde o início da formação dos frutos até a maturação.

\section{RESULTADOS E DISCUSSÃO}

Quanto à morfologia floral, apresenta: planta hermafrodita, flor vistosa, solitária, rosada, situada terminalmente nos ramos, pedunculada, cíclica, de simetria radial, diperiantada, heteroclamídea, polistêmone, hipógina; não apresenta brácteas, cálice dissépalo, pentâmero, corola do tipo rosácea, com pétalas carnosas, androceu com numerosos estames dispostos em cinco feixes, homodínamo, dialistêmone, com estames simples, antera apicefixa, de deiscência longitudinal, introrsa e com uma só teca, gineceu sincarpico, pluricarpelar, estilete terminal, estigma ramificado (pentapartido) e ovário plurilocular.

A descrição morfológica da espécie está de acordo com a de Batista e Jardim (2001), que também caracterizaram a morfologia de Platonia insignis Mart. em ambiente de vegetação secudária. Maués e Venturieri (1996) destacam a coloração externa das pétalas rosadas que varia do rosa claro ao rosa intenso no final da floração. Cavalcante (1976) dimensiona o comprimento da flor do bacurizerio em $7 \mathrm{~cm}$ e destaca que a cor rósea tem efeito ornamental, o que, provavelmente, contribui para atração de visitantes.

A antese ocorreu nas primeiras horas do dia, por volta das $6 \mathrm{~h}$, fato que, possivelmente, está associado ao hábito dos agentes visitantes.

\section{Floração e frutificação}

A partir das primeiras observações em agosto foi possível determinar o estágio de plena floração de todos os indivíduos observados, que se estendeu até o mês de dezembro em diferentes fenofases, coincidindo com o período de estiagem da região. Em seguida, voltaram a florescer de abril até julho de 2002 (Figura 1). É importante destacar que a presença de botão floral, flor e pétala no chão com vestígio de predação foram comuns, assim como o grande número de ovários em desenvolvimento.

Em novembro iniciou a frutificação que se estendeu até março durante o período chuvoso (dezembro, janeiro, fevereiro e março). De dezembro a março, a frutificação atingiu cerca de $50 \%$ em frutos maduros. A duração da frutificação foi de, aproximadamente, cinco meses (Figura 1). A queda

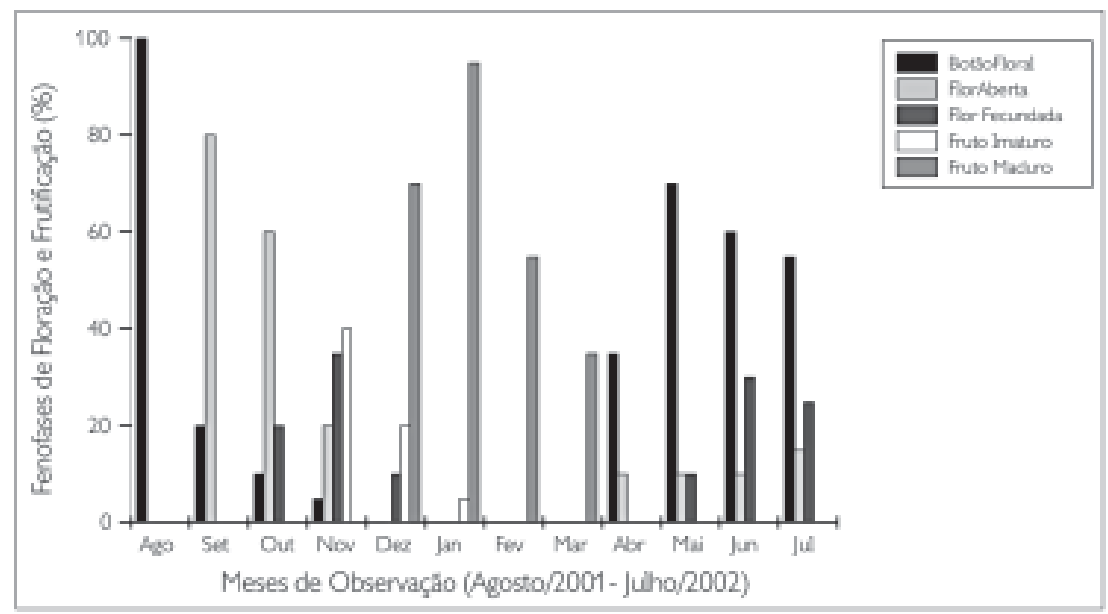

Figura 1. Fenofases de floração e frutificação de Platonia insignis Mart. no período de agosto de 2001 a julho de 2002 na comunidade de Benjamin Constant, município de Bragança, estado do Pará.

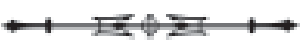


dos frutos iniciou-se em março e estendeu-se até meados de abril, no período chuvoso da região. A perda de frutos após a fecundação pode ser explicada pelo grau de predação na fase inical dos mesmos.

Lorenzi (2000) afirma que Platonia insignis Mart. floresce durante os meses de junho a setembro. Segundo Pires O’Brien e O’Brien (1995) as características ambientais, interagindo com as condições climáticas e edáficas, podem influenciar na floração durante os períodos secos. florescimento da maioria das árvores, durante o período seco, foi constatado nos estudos de Alencar, Almeida e Fernandes (1979), na Reserva Ducke.

Quanto ao período de frutificação, Lorenzi (2000) relata que a maturação dos frutos ocorre no período de dezembro até meados de março. Resultados aproximados foram encontrados por Cavalcante (1976), afirmando que a queda dos frutos inicia em dezembro e estende-se até maio e o clímax da safra é fevereiro e março. Alencar, Almeida e Fernandes (1979) e Alencar (1994) verificaram, na Reserva Ducke, dentre mais de cinqüenta espécies, que a maioria apresentou frutos maduros e frutos caindo na estação chuvosa.

\section{CONCLUSÕES}

Platonia insignis Mart. não apresentou diferenças quanto à morfologia floral em comparação às outras descrições. As fenofases apresentaram sincronismo parcial, ou seja, a floração e frutificação tiveram duração de cinco meses, correspondendo, respectivamente, com as épocas de menor e maior índice pluviométrico. As fenofases podem estar relacionadas às respectivas necessidades de cada evento, ou seja, para disponibilizar aos agentes visitantes um maior recurso floral. Outro fator é que o período seco interfere positivamente na floração. $\bigcirc$ contrário ocorre para frutificação, que passa a maior parte de seu desenvolvimento no período de maior precipitação. Provavelmente esta relação com a disponibilidade de água influencia no tempo de duração de cada fenofase e no padrão anual para a espécie.

\section{AGRADECIMENTOS}

À Profa. Dra. Manoela Fernandes Ferreira da Silva, pelo apoio logístico e financeiro concedidos para a realização desta pesquisa.

\section{REFERÊNCIAS}

ALENCAR, J. C.; ALMEIDA, R. F.; FERNANDES, N. P. 1979. Fenologia de espécies florestais em floresta tropical úmida de terra firme na Amazônia Central. Acta Amazonica, v. 9, n. 1, p. 163-198.

ALENCAR, J. C. 1994. Fenologia de cinco espécies arbóreas tropicais de sapotaceae correlacionada a variáveis climáticas na reserva DUCKE, Manaus, AM. Acta Amazonica, v. 24, n. 3/4, p. 161-183.

BATISTA, F. de J.; JARDIM, M. A. G. 2001. Biologia floral do bacuri (Platonia insignis Mart.) em áreas de vegetação secundária no município de Bragança, Estado do Pará. In: CONGRESSO NACIONAL DE BOTÂNICA, 52., REUNIÃO NORDESTINA DE BOTÂNICA, 24., João Pessoa. Resumos... João Pessoa: Sociedade Botânica do Brasil. 176 p.

CARVALHEIRO, K. et al. 2001. Agricultura familiar do nordeste paraense: informações preliminares como contribuição ao manejo sustentável da capoeira. Documentos, Belém, n. 78. Embrapa Amazônia Oriental, CIFOR.

CAVALCANTE, P. B. 1976. Frutas comestíveis da Amazônia. 3. ed. Belém: INPA. p. 55-57. il.

CAVALCANTE, P. B. 1988. Frutas comestíveis da Amazônia. 4. ed. Belém: Museu Paraense Emílio Goeldi, 48-50 p. il.

LORENZI, H. 2000. Árvores brasileiras: manual de identificação e cultivo de plantas arbóreas nativas do Brasil. 3. ed. Nova Odessa, SP: Instituto Plantarum. 125 p. v. 1. il.

MAUÉS, M. M.; VENTURIERI, G. C. 1996. Ecologia de polinização do bacurizeiro (P. insignis Mart.) Clusiaceae. Belém: EMBRAPA-CPATU. (Boletim de pesquisa, 170).

MONTSERRAT RIOS. 2001. Benefícios das plantas da capoeira para a comunidade de Benjamin Constant, Pará, Amazônia Brasileira. Belém: CIFOR. 54 p. il.

PIRES O'BRIEN, M. J.; O'BRIEN, C. M. 1995. Ecologia e modelamento de florestas tropicais. Belém: FCAP. 303-350 p. Serviço de documentação e Informação.

SECTAM. 1999. Coordenadoria de Estatistica Estadual CEE: setor de coleta e tratamento de dados. Perfis Municipais: Bragança-Pará. 39 p.

VIDAL, W. N.; RODRIGUES, M. R. 2000. Botânica: Organografia. 4. ed. Viçosa: UFV. 124 p. il.

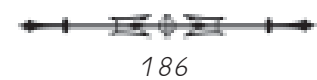

